\title{
Estudo Microestrutural de Aço Carbono Soldado com o Processo Arco Submerso e Adições de Fe-Ti
}

\author{
(Microstructural Study of Carbon Steel Welded with the Submerged Arc Process and Additions of Fe-Ti)
}

\author{
Aleir Fontana De Paris ${ }^{1}$, Francisco Mulazzani ${ }^{1}$, Jean-Michel De Paris ${ }^{1}$ \\ ${ }^{1}$ Universidade Federal de Santa Maria, Departamento de Engenharia Mecânica, Santa Maria, RS, Brasil, paris@ufsm.br
}

\begin{abstract}
Resumo
Os cordões de solda apresentam normalmente uma estrutura colunar grosseira, o que diminui as propriedades mecânicas do conjunto soldado. No caso da soldagem com arco submerso, o emprego de alta energia proporciona uma solda com características peculiares como a elevada taxa de fusão e consequentemente grande volume de metal fundido. Foi comprovado que a redução no tamanho el ou modificações na forma dos cristais obtidos aumenta a tenacidade da junta soldada. Estudos realizados mostraram que a adição de titânio, até certo limite, modificaria a microestrutura obtida bem como o tamanho dos grãos solidificados. Neste trabalho, foi empregada uma liga metálica de Fe-Ti adicionada no momento de soldagem, tipo bead-on-plate, sobre aço estrutural ASTM A 36, com espessura de $10 \mathrm{~mm}$. As adições de titânio variaram entre 0,48 ppm e 29,1 ppm, e a soldagem foi executada com uma energia de 1170 $\mathrm{kJ} / \mathrm{m}$. Os resultados mostraram modificações da fase ferrita acicular bem como da ferrita poligonal presentes na solda.
\end{abstract}

Palavras-chave: Arco Submerso; Liga Fe-Ti; Microestrutura; Propriedades Mecânicas.

Abstract: The welds usually have a coarse columnar structure, which reduces the mechanical properties of welded assembly. In the case of submerged arc welding, the use of high-energy provides a weld with specific characteristics such as high melting rate and consequently a large volume of molten metal. It was established that the reduction in size and/or changes in the shape of the crystals obtained increases the toughness of the weld. Studies have shown that the addition of titanium to a certain limit, modify the microstructure obtained and the size of the grains solidified. In this study, we used an alloy of Fe-Ti added at the time of welding-type bead-on-plate on structural steel ASTM A 36 with a thickness of $10 \mathrm{~mm}$. The additions of titanium ranged between 0.48 ppm and 29.1 ppm, and welding was performed with an energy of $1170 \mathrm{~kJ} / \mathrm{m}$ The results showed changes in the phase acicular ferrite and polygonal ferrite present in the weld.

Key-words: Submerged Arc Welding; Fe-Ti alloy; Microstructure; Mechanical Properties.

\section{Introdução}

Na soldagem empregando o processo arco submerso como o aporte de energia é elevado, devido às grandes intensidades de corrente utilizadas, a estrutura resultante no cordão de solda é colunar grosseira com microestrutura composta de ferrita de contorno de grão, poligonal e acicular.

Para melhorar as propriedades da junta soldada, especificamente a tenacidade, um aumento da ferrita acicular no cordão de solda é comprovadamente benéfico sem diminuição da resistência mecânica.

A Figura 1 mostra de forma esquemática o caminho para propagação de fratura por clivagem. Este é função da orientação espacial das placas de ferrita de contorno de grão e intragranular [1]. De acordo com a figura, a ferrita de contorno de grão (tal como ferrita Widmanstätten ou bainita superior) proporciona um caminho preferencial de propagação de trincas no grão. No caso de ferrita acicular, como esta tem uma orientação cristalográfica

(Recebido em 29/02/2012; Texto final em 07/03/2012).

Artigo originalmente publicado no CONSOLDA 2011 ao acaso, o caminho de propagação de trincas por clivagem é retardado sendo este um dos mecanismos pelo qual a tenacidade é melhorada nas soldas [2].

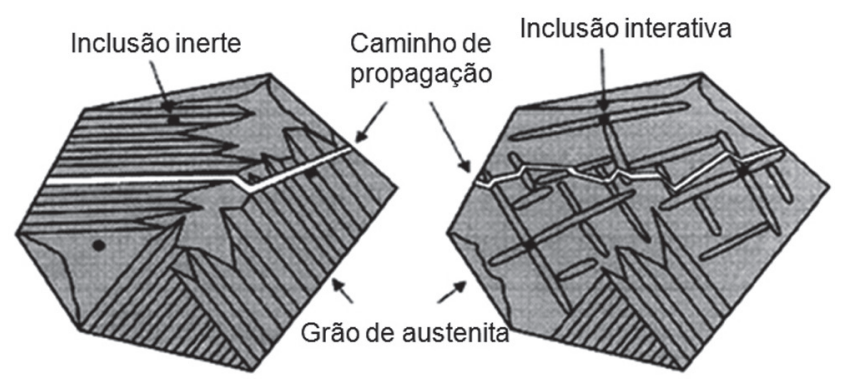

Figura 1. Ilustração esquemática do caminho de propagação de fratura de clivagem nos grãos de aço com ferrita de contorno de grão e ferrita acicular [1]

A Figura 2 mostra as mudanças de fases que ocorrem no metal da solda de aços e descreve a formação de ferrita acicular no contexto da evolução microestrutural [3]. Na faixa de temperatura de resfriamento de $2000-1700^{\circ} \mathrm{K}$, Figura 2(a), 
o oxigênio dissolvido e os elementos desoxidantes no metal líquido reagem e formam inclusões complexas de óxidos. Diminuindo a temperatura de $1700-1600^{\circ} \mathrm{K}$, Figura 2(b), inicia a solidificação de ferrita $\delta$ que envolve as inclusões; esta ferrita $\delta$ se transforma em austenita. De $1600-800^{\circ} \mathrm{K}$, Figura 2(c), pode ocorrer crescimento do grão de austenita. Com a diminuição da temperatura de $800-300^{\circ} \mathrm{K}$, Figura $2(\mathrm{~d})$ a $2(\mathrm{~g})$, a austenita se decompõe em diferentes morfologias de ferrita. A decomposição da austenita para ferrita, Figura 1(d) e 1(e), inicia com a formação de ferrita alotriomórfica nos contornos do grão de austenita e eventual cobertura dos mesmos. Com o resfriamento contínuo, Figura 1(f), ferrita Widmanstätten nucleia nos contornos $\alpha / \gamma$ e se estende no interior do grão não transformado da austenita. Com resfriamento posterior, Figura 1(g), a ferrita acicular nucleia nas inclusões.

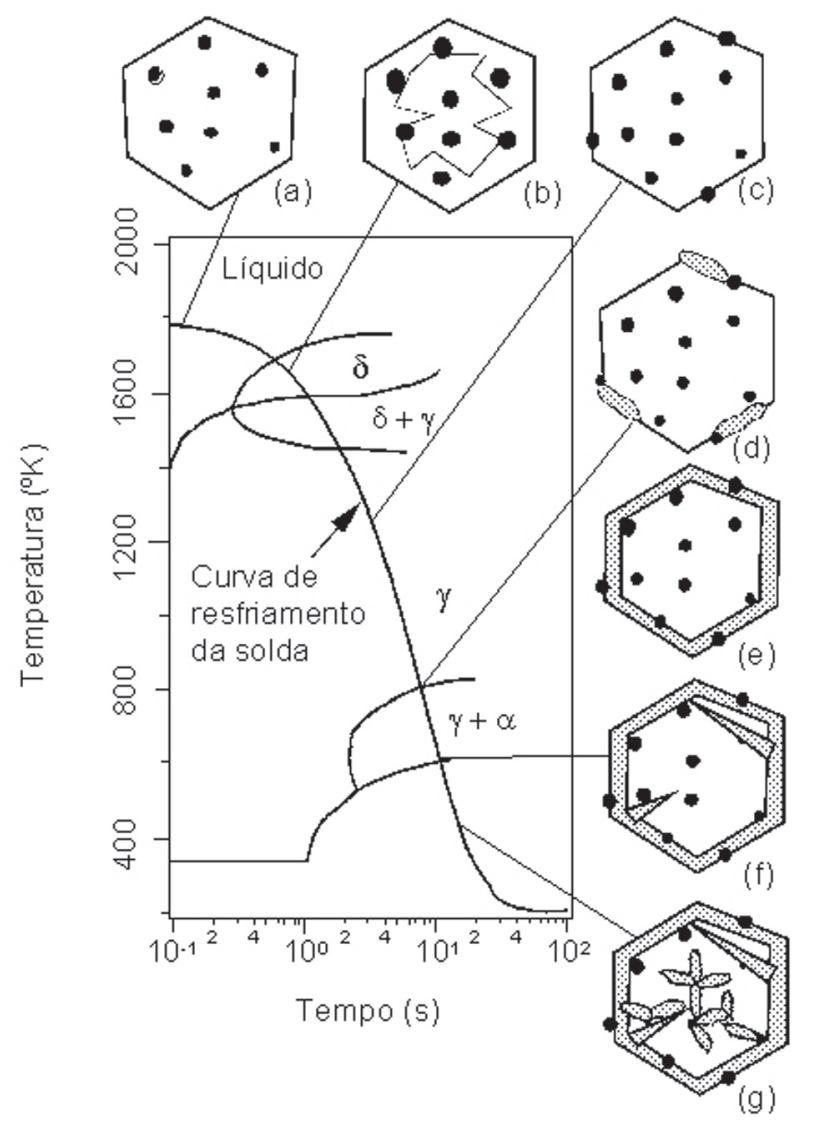

Figura 2. Ilustração esquemática da curva de resfriamento do metal de solda mostrando as diferentes fases que podem ocorrer [3].

No caso de inclusões não ativamente potentes, poderia se formar bainita da austenita remanescente ao invés de ferrita acicular. Para temperaturas próximas da ambiente, qualquer austenita remanescente pode, completamente ou parcialmente, se transformar em martensita.

A formação da estrutura de ferrita acicular pode ser provocada pela adição controlada de elementos químicos microligantes nos aços, por exemplo: Ti, Al, Nb, V, O, N, Ce, B e S [4]. De acordo com [5], o potencial de nucleação intragranular varia com o tipo de inclusões e as mais efetivas são as que contem $\mathrm{Ti}, \mathrm{Ca}$ e $\mathrm{S}$. Outra característica importante seria o tamanho das inclusões, quanto maiores se tornariam sítios preferenciais da nucleação da ferrita acicular, resultando na transição entre ser ou não ser nucleante em função do seu tamanho [6]. O tamanho mínimo das inclusões para assegurar uma boa nucleação intragranular seria de $0,40-0,80 \mu \mathrm{m}[5]$.

Os fatores que afetam a formação de ferrita acicular seriam de acordo com [4]: a composição química do aço, taxa de resfriamento na faixa de temperatura $800-500^{\circ} \mathrm{C}$, tamanho do grão de austenita e as inclusões na solda.

Os mecanismos de formação da ferrita acicular nas inclusões, sugeridos na literatura seriam:

- redução da energia interfacial e nucleação simples heterogênea na superfície das inclusões $[6,7,8]$;

- nucleação epitaxial nas inclusões, a qual tem boa coerência com a ferrita $[9,10]$;

- nucleação devido as tensões internas nas inclusões a qual é associada com diferentes coeficientes de expansão térmica nas inclusões e na matriz metálica [11];

- nucleação devido a depleção dos elementos do soluto na matriz próximo das inclusões $[12,13]$.

No caso da soldagem com o processo arco submerso, a estrutura grosseira resultante no cordão de solda é prejudicial para a qualidade da junta soldada. A adição de elementos químicos que tenham um grande potencial de refinamento e/ou formação de ferrita acicular aumentaria a resistência à tenacidade da junta soldada. Os primeiros trabalhos empregando o titânio como inoculante na soldagem de aços C-Mn, foram realizadas por $[14,15,16,17]$. As técnicas utilizadas foram através de um metal de adição sob a forma de tubo de aço carbono contendo Fe-Ti $[14,15,16]$ e a adição sob a forma de pó ou arame diretamente sobre a junta a ser soldada [17]. As estruturas obtidas foram variadas de acordo com a porcentagem de titânio adicionada. Outros autores obtiveram aumento da ferrita acicular com a adição de Ti-B na soldagem de aços carbono, obtendo tenacidade da junta soldada $70 \%$ superior as soldas sem adição [18]. A adição de $3 \%$ de titânio ao ferro suprimiria completamente a formação da fase $\gamma$ quando a fase $\alpha$ é aquecida acima de seu ponto de transformação normal $\alpha-\gamma$, de $921^{\circ} \mathrm{C}$ [19].

O objetivo deste trabalho é analisar a influência da adição de ferro-titânio, na soldagem com arco submerso de aço estrutural, para verificar a formação de ferrita acicular e refino de grão em função das inclusões. Para facilitar a diluição no metal da solda, o Fe-Ti foi adicionado sob a forma granular. A escolha do titânio como inoculante, é sua efetividade como refinador de grão e formador de ferrita.

\section{Materiais e Métodos}

A soldagem foi realizada sobre aço carbono estrutural ASTM A36 com espessura de $10 \mathrm{~mm}$, cortado em peças de 70 x $200 \mathrm{~mm}$. Os cordões foram tipo depositado (bead-on-plate), empregando um equipamento de soldagem a arco submerso com fonte inversora, mecanizado (trator), marca Keyue modelo MZ1000, com corrente contínua e polaridade direta (eletrodo 
Tabela 1. Composição química nominal dos aços ASTM A36.

\begin{tabular}{c|c|c|c|c|c|c}
\hline $\mathrm{C}$ & $\mathrm{Cu}$ & $\mathrm{Mn}$ & $\mathrm{Si}$ & $\mathrm{P}$ & $\mathrm{S}$ & $\mathrm{Fe}$ \\
\hline $0,29 \%$ & $0,20 \%$ & $1,00 \%$ & $0,28 \%$ & $>0,04 \%$ & $>0,05 \%$ & Rest. \\
\hline
\end{tabular}

Tabela 2. Composição química do inoculante a base de Fe-Ti.

\begin{tabular}{c|c|c|c|c|c|c|c|c}
\hline Elemento & $\mathrm{Ti}$ & $\mathrm{Al}$ & $\mathrm{Si}$ & $\mathrm{C}$ & $\mathrm{P}$ & $\mathrm{S}$ & $\mathrm{Mn}$ & $\mathrm{Fe}$ \\
\hline$\%$ & 28,64 & 7,40 & 1,51 & 0,05 & 0,003 & 0,020 & 1,46 & Rest. \\
\hline
\end{tabular}

Tabela 3. Granulometria da liga Fe-Ti.

\begin{tabular}{c|c|c|c}
\hline Peneira $(\mathrm{mm} / \mathrm{mesh})$ & 12 & 60 & -60 \\
\hline$\%$ retida & 0 & 95 & 5 \\
\hline
\end{tabular}

Tabela 4. Numeração das amostras e quantidades de inoculante.

\begin{tabular}{c|c|c|c|c|c}
\hline Amostra & CP1 & CP2 & CP3 & CP4 & CP5 \\
\hline Peso de Fe-Ti (gramas) & 0 & 0,01 & 0,10 & 0,50 & 1,0 \\
\hline
\end{tabular}

positivo). A Tabela 1 mostra a composição química nominal do metal de base.

$\mathrm{O}$ arame de deposição empregado, de diâmetro $3,25 \mathrm{~mm}$, foi o classificado pela norma AWS A5.23 como EM12K e o fluxo do tipo neutro F7A2.

Os parâmetros de solda utilizados foram: intensidade de corrente de $500 \mathrm{~A}$, tensão do arco $32 \mathrm{~V}$, velocidade de soldagem $60 \mathrm{~cm} / \mathrm{min}$ e distância bocal-peça de $15 \mathrm{~mm}$. A técnica utilizada para a inoculação do Ti foi a mesma empregada por Heintze [17], a deposição de quantidade controlada de Fe-Ti sobre a peça a ser soldada. A composição química do pó granular FeTi está mostrada na Tabela 2. A granulometria foi selecionada de acordo com aquela utilizada para o fluxo de soldagem e está mostrada na Tabela 3.

Foram efetuados cinco cordões de solda com e sem adição do inoculante, com a quantidade (peso) mostrada na Tabela 4, em uma distância pré-determinada.

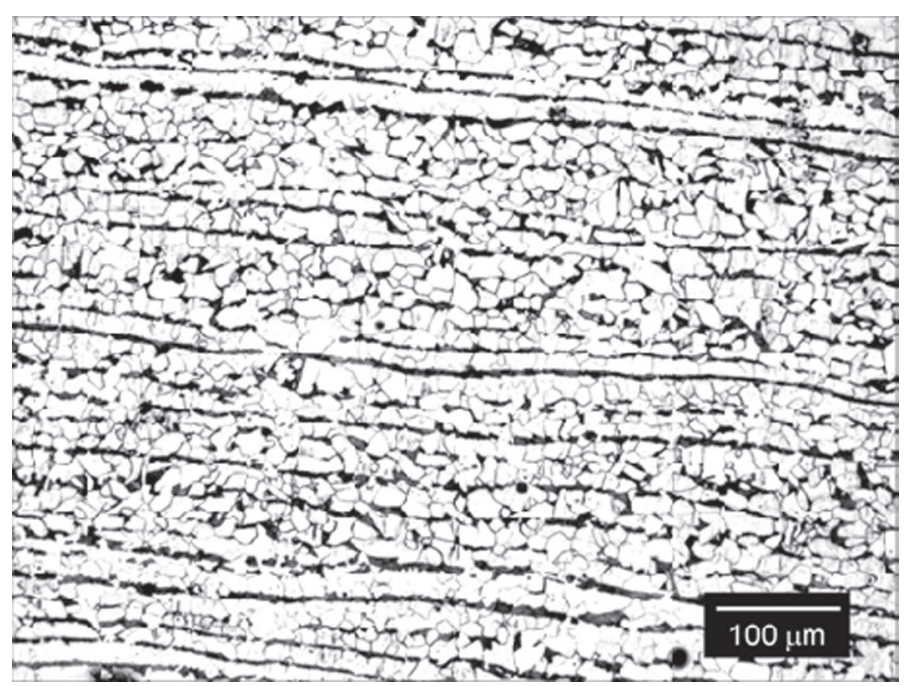

Figura 3. Microestrutura do metal de base.

Para determinar a porcentagem de Ti que foi adicionada, foi calculada a área transversal dos cordões de solda, medida com o uso do software Image Tools, e com uma distância pré-determinada na linha de fusão, calculado o volume de metal fundido. Sobre esta linha foi distribuído, da forma mais homogênea possível, o peso do inoculante correspondente. Os teores de Ti proporcionais foram $0,48 \mathrm{ppm}, 6,20 \mathrm{ppm}, 14,1 \mathrm{ppm}$ e $29,1 \mathrm{ppm}$.

Para a análise da microestrutura forma empregadas microscopia ótica e eletrônica de varredura (MEV). O perfil de microdureza Vickers dos cordões obtidos foi efetuado ao longo da seção transversal empregando uma carga de 300 gramas e tempo de aplicação de 10 segundos.

As amostras foram atacadas com nital 3\%. A Figura 3 apresenta a microestrutura do metal de base composto de ferrita e perlita.

\section{Resultados e Discussão}

A Figura 4 mostra as micrografias do metal de solda, somente polidas para as amostras sem inoculação CP1 (a), com adição de 0,48 ppm CP2 (b) e 29,1 ppm de titânio CP 5 (c).

As imagens das amostras CP3 e CP4 não foram apresentadas, pois o aumento do tamanho e quantidade das inclusões foi gradual, sendo aquelas apresentadas na Figura 4 mais representativas, já que foram os extremos. Na Figura 4(a) observa-se que o metal de solda sem inoculação CP1 apresenta poucas inclusões com pequenos diâmetros. Com a adição de 0,48 ppm de $\mathrm{Ti}$, as inclusões aparecem em grande número dispersas em toda a matriz, com dimensões maiores, Figura 4(b). Com o aumento da porcentagem de Ti, 29,1 ppm, a quantidade de inclusões manteve-se idêntica porem com algumas apresentando grande aumento na suas dimensões, Figura 4(c). Isto mostra, primeiramente, que houve passagem de titânio para o cordão de solda com a técnica empregada, e em segundo lugar, que as inclusões não aumentaram em quantidade, mas se precipitaram com dimensões maiores.

A Figura 5 mostra a microestrutura dos cordões de solda após ataque adequado. Como pode ser observado, há um aumento gradual da quantidade de ferrita acicular nas soldas 


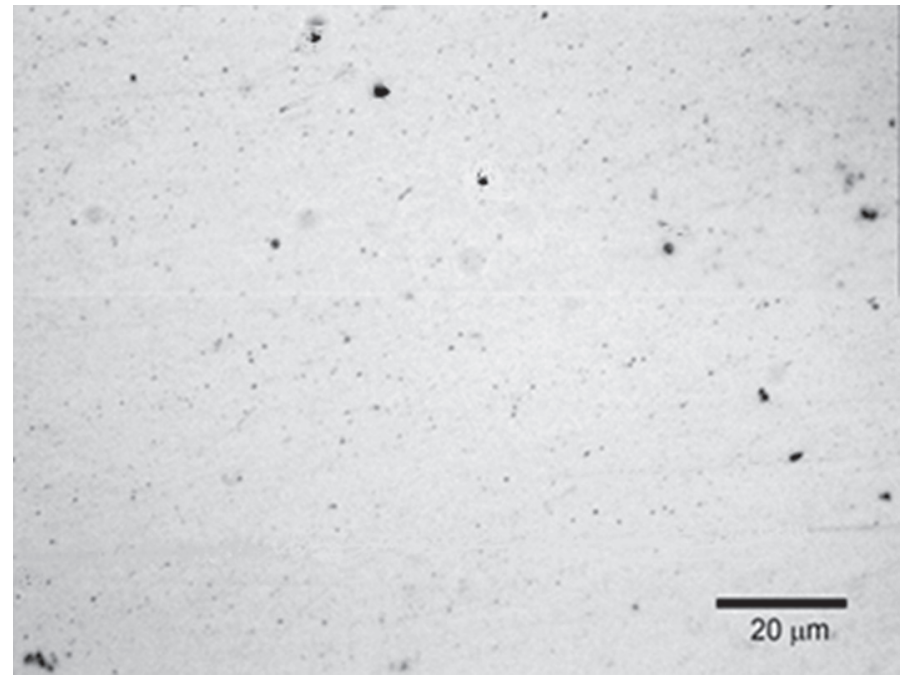

(a)

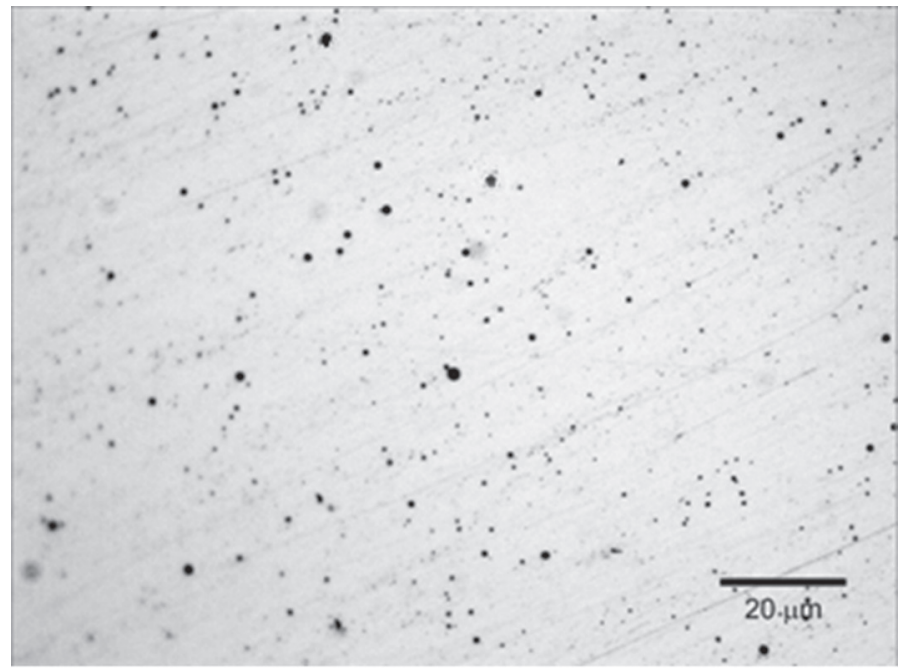

(b)

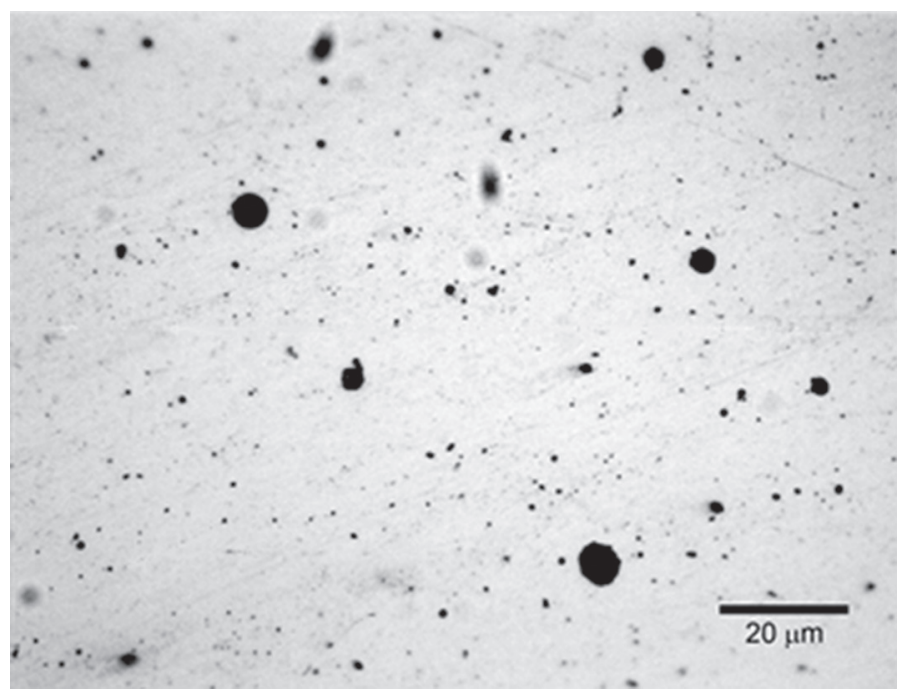

(c)

Figura 4. Imagens das amostras CP1 (a), CP2 (b) e CP(5) polidas sem ataque.

e também uma diminuição no tamanho e quantidade da ferrita de contorno de grão. Estes resultados estão de acordo com os encontrados na literatura [17,18]. Com a adição de 29,1 ppm de titânio, Figura 5 (CP5), a microestrutura obtida é totalmente acicular com a provável presença de bainita. Este resultado é confirmado pelos valores de microdureza encontrados. A Figura 6 mostra os perfis de microdureza ao longo da seção transversal dos cordões de solda das amostras CP1, CP2 e CP5, por serem mais significativas.

Com maiores ampliações da microestrutura, Figura 7, pode-se verificar que as dimensões das inclusões ficaram na faixa de 1 a $8 \mu \mathrm{m}$. Estes resultados estão bem acima daqueles sugeridos por [6], como sendo o tamanho mínimo para uma boa nucleação intragranular. Segundo os autores [6], a probabilidade de ocorrência da ferrita acicular aumentaria com o tamanho da inclusão a partir de 0,4 a $0,8 \mu \mathrm{m}$ e atingiria a probabilidade 1,0 com um diâmetro de 1,1 $\mu \mathrm{m}$. Com maiores aumentos do tamanho das inclusões não haveria o aumento da ferrita acicular, mantendo-se constante sem alterações, Figura 8. Resultados semelhantes foram encontrados por Ricks et al [7]. Conforme Sarma et al [4] esta faixa de tamanho de inclusões seria o normal encontrado em aços carbono, com algumas, mas nem todas, atuando como formadores de ferrita acicular.

Os valores encontrados neste trabalho está de acordo com outros resultados encontrados em publicações [1,10,13,20,21]. Desta forma, quanto maior o tamanho das inclusões, maior o potencial de formação de ferrita acicular.

Analisando as inclusões por espectrometria de energia dispersiva (EDS) foram encontradas as presenças de $\mathrm{Ti}, \mathrm{Al}$ e em pequenas proporções o oxigênio, como mostra o espectro da Figura 9.

O espectro de EDS, em linha, confirma a presença de prováveis óxidos de alumínio e de titânio. Segundo [22] a oxidação preferencial se daria com o alumínio e posteriormente com o titânio, já que termodinamicamente o processo é mais favorável para o alumínio. Isto pode ser verificado na Figura 7, onde se nota a presença de duas fases distintas na inclusão. 


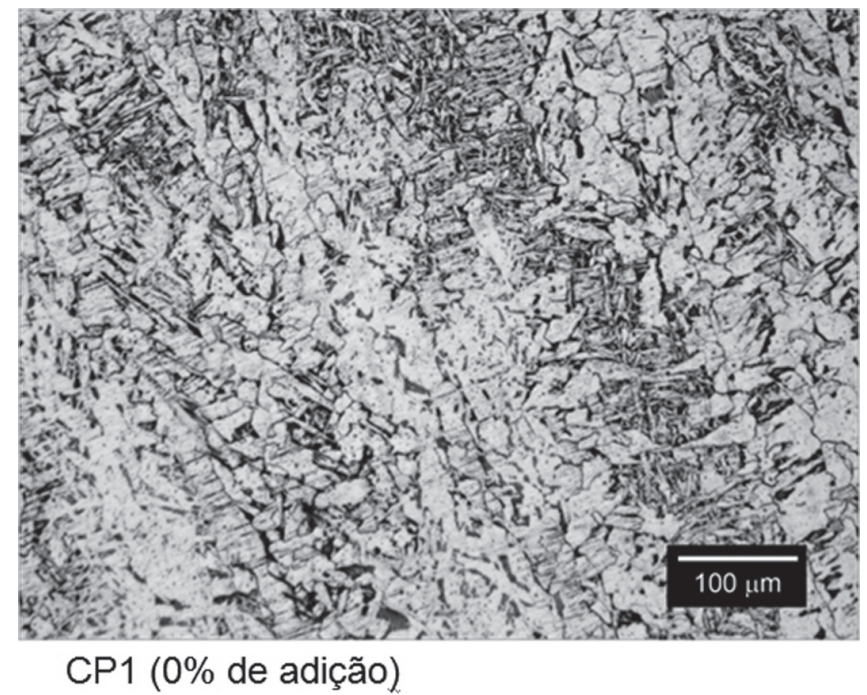

(a)

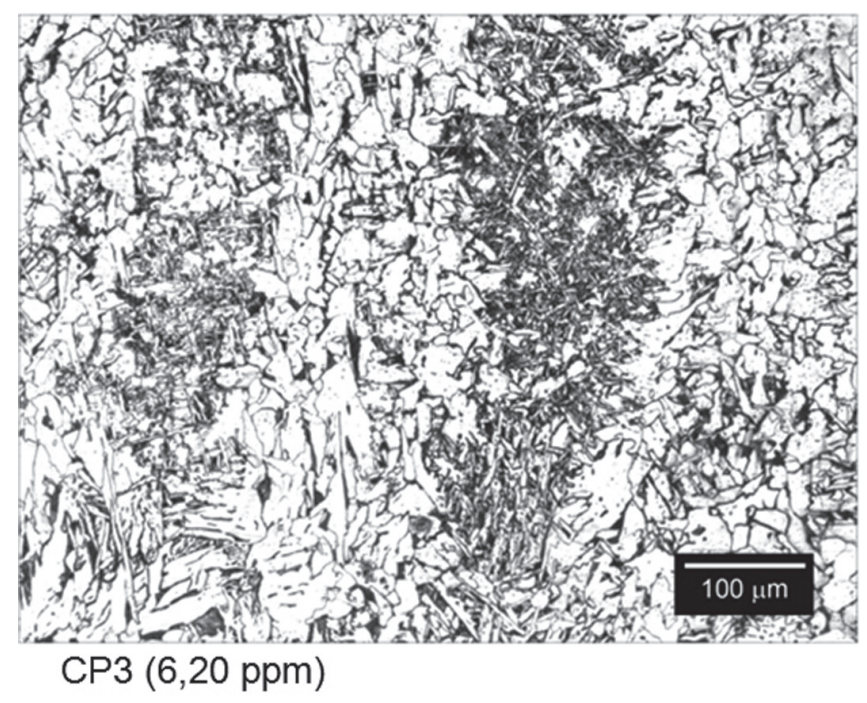

(c)

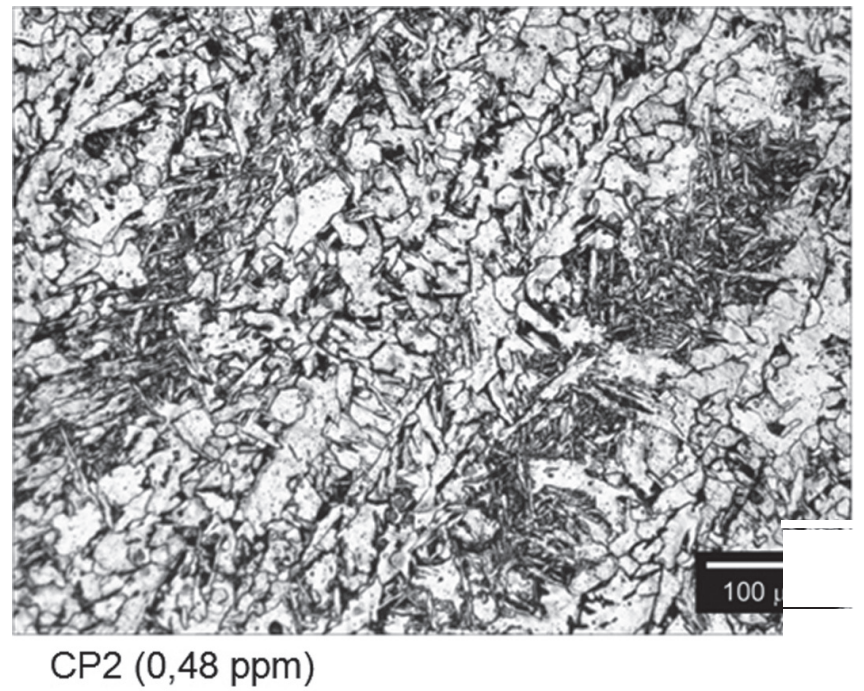

(b)

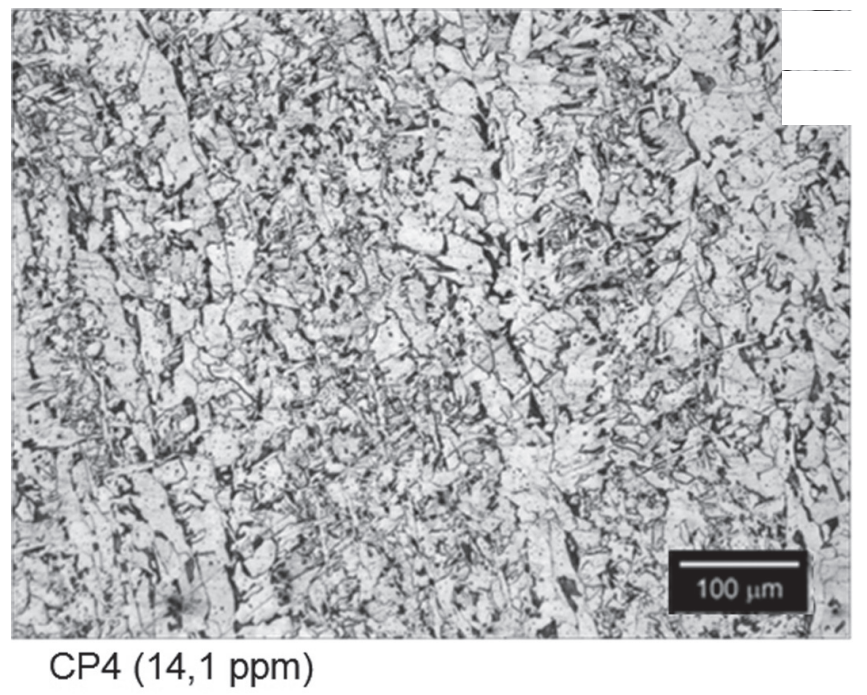

(d)

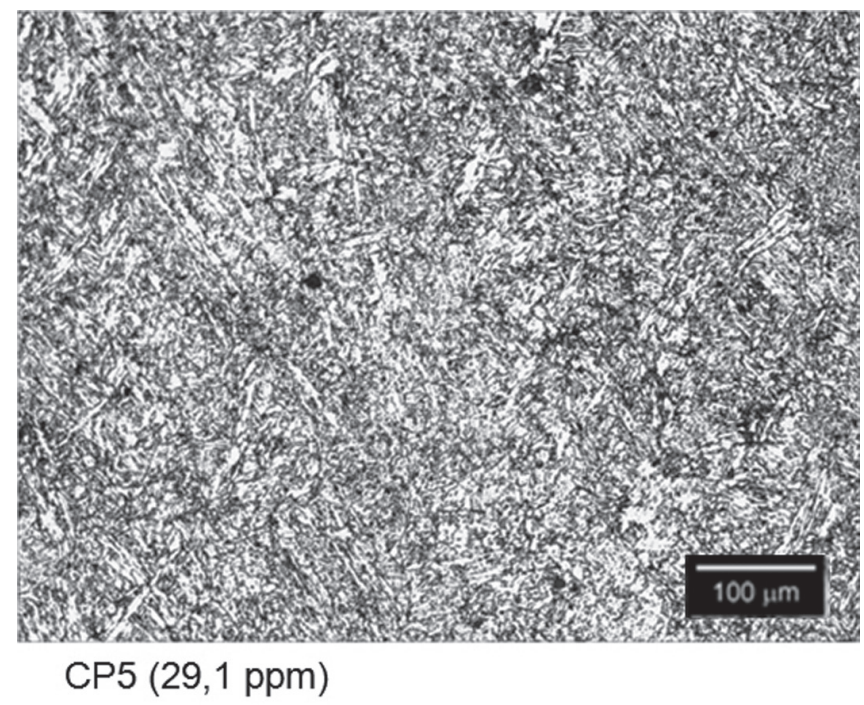

(e)

Figura 5. Microestruturas dos cordões de solda. 


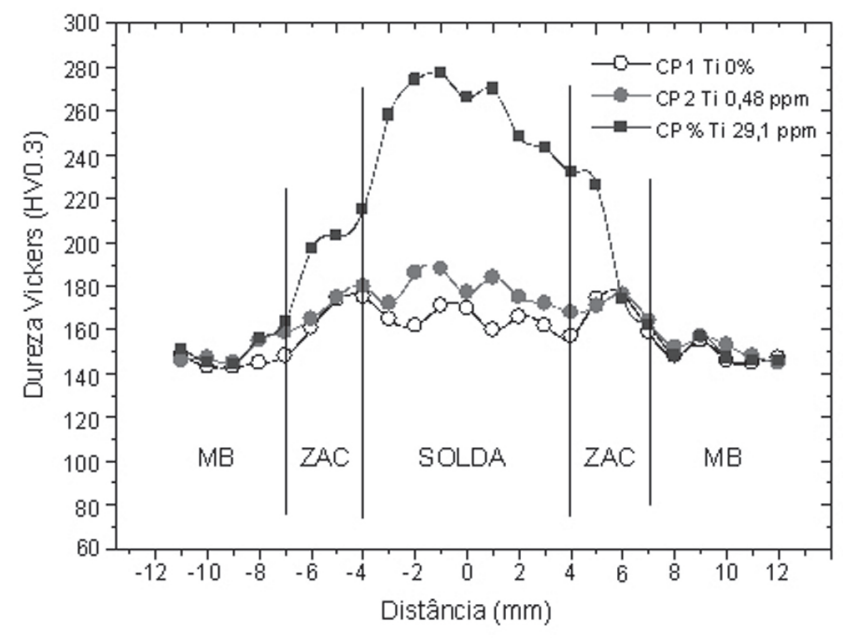

Figura 6. Perfil da microdureza ao longo da seção transversal da solda.

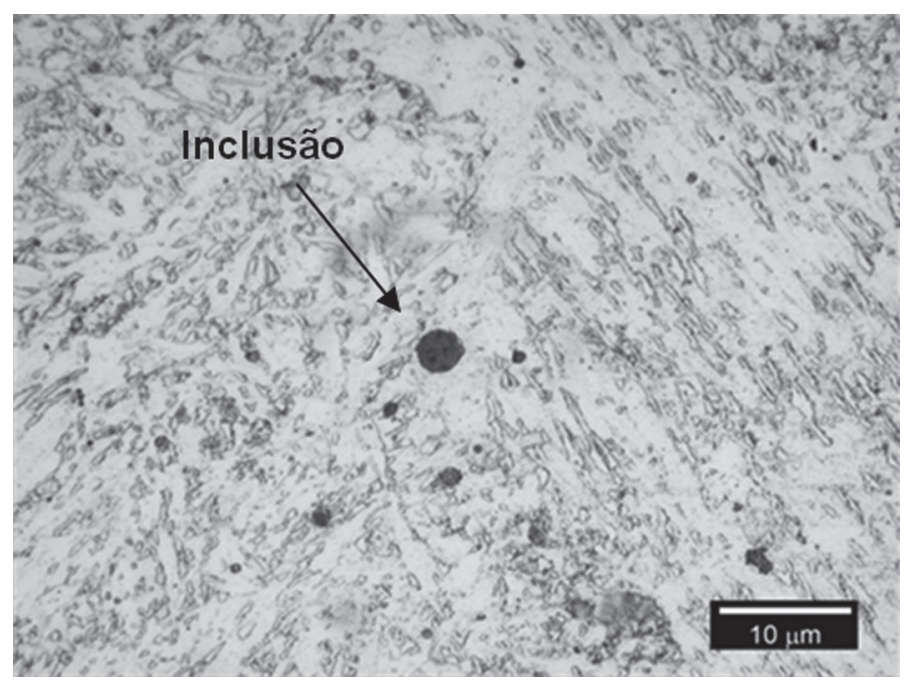

(a)

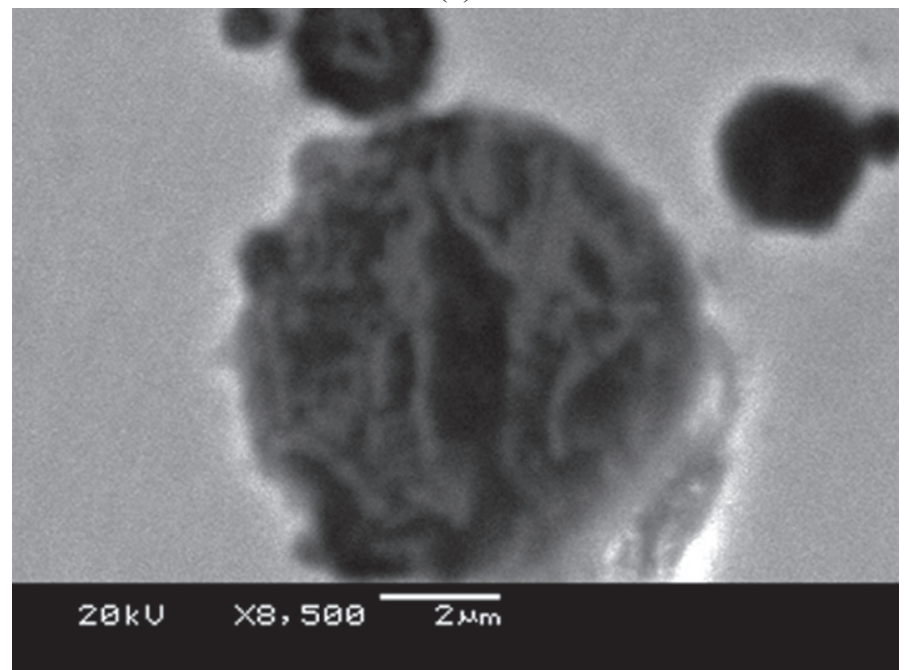

(b)

Figura 7. Microscopia ótica e eletrônica de varredura de inclusão na solda.

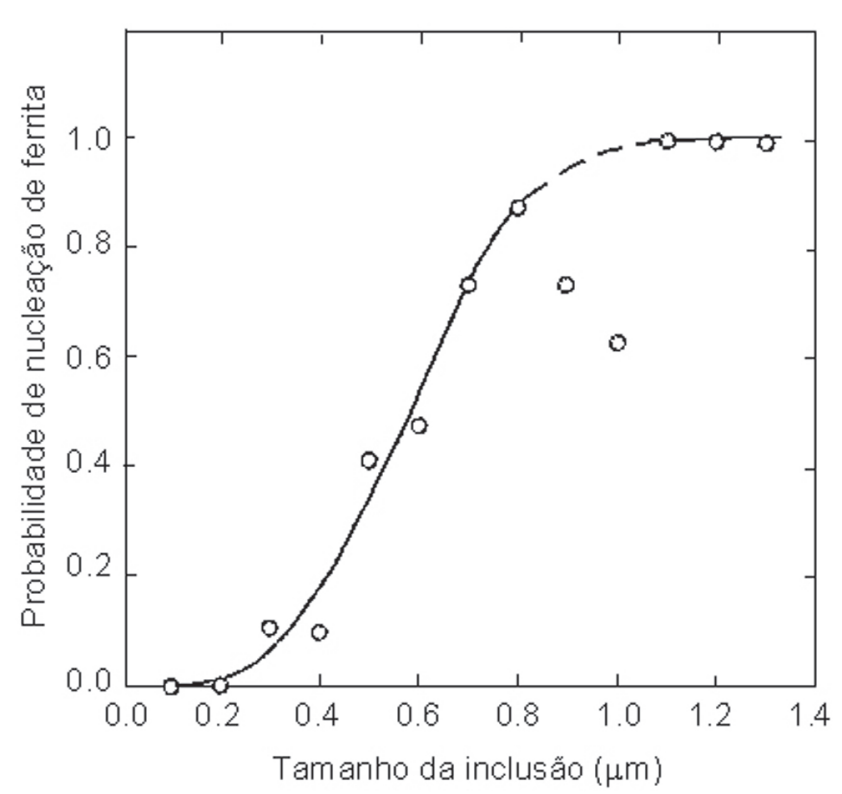

Figura 8. Efeito do tamanho da inclusão na probabilidade de nucleação de ferrita [6].

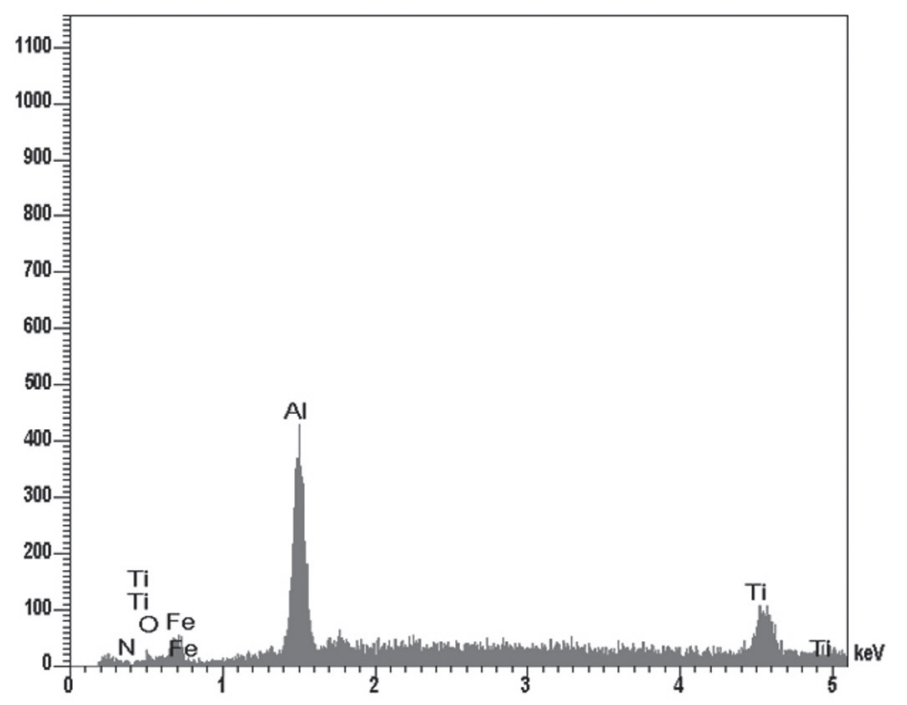

Figura 9. Espectro EDS dos elementos químicos presentes nas inclusões.

\section{Conclusões}

Com os resultados obtidos neste trabalho e nas publicações consultadas, o titânio é um elemento químico que favorece potencialmente a formação de ferrita acicular. Pelas adições de Ti utilizadas, verifica-se que o aumento da proporção do mesmo na solda implica no tamanho das inclusões e como consequência aumento na formação da ferrita acicular. A técnica empregada não é apropriada para ser utilizada na indústria, mas leva a resultados que podem ser utilizados na fabricação do fluxo de proteção. $\mathrm{O}$ aumento de $\mathrm{Fe}$-Ti no mesmo resultaria, em função dos resultados obtidos, a presença provável de um número maior de inclusões na solda e consequentemente maior presença de 
ferrita acicular. A quantidade otimizada da liga Fe-Ti ainda é objeto de estudos. Um teste importante que não foi realizado e seria de vital importância, é verificar se esta inoculação com a liga e quantidades utilizadas, melhoria a tenacidade da junta soldada.

\section{Agradecimentos}

Os autores agradecem as empresas Lincoln Electric do Brasil pelo fornecimento do arame e fluxo de solda, e a empresa Cofel pela liga Fe-Ti.

\section{Referências Bibliográficas}

[1] EIJK, C.; GRONG, O.; KJELEN, J. Quantification on inclusion-stimulated ferrite nucleation in wrought steel using the SEM-EBSD technique, In: International Conference on SolidSolid Phase Transformation '99, KYOTO, Japan, p.1-4, 24-28 May, 1999.

[2] BHADESHIA, H.K.D.H. Bainite in Steels: Transformations, Microstructure and properties, Ed. Institute of Materials, $3^{\mathrm{a}}$ ed., 400 p, 2001.

[3] BABU, S.S. The mechanism of acicular ferrite in weld deposits. Current Opinion in Solid State and Materials Science, v.8, p.267-278, 2004.

[4] SARMA, D.S.; KARASEV, A.V.; JÖNSSON, P.G. On the role of non-metallic inclusions in the nucleation of acicular ferrite in steels, ISIJ Int., v.49, n.7, p.1063-1074, 2009.

[5] LEE, J-L. Evaluation of the nucleation potential of intragranular acicular ferrite in steel weldments, Acta Metall. Mater., v.42, n.10, p.3291-3298, 1994.

[6] LEE, T-K.et al. Effect of inclusion size on the nucleation of acicular ferrite in welds, ISIJ Int., v.40, n.12, p.1260-1268, 2000. [7] RICKS, R.A.; HOWELL, P.R.; BARRITE, G.S. The nature of acicular ferrite in HSLA steel welds metals, J. Mater. Sci., v.17, p.732-740, 1982 .

[8] ZHANG, Z.; FARRAR, R.A. Role of non-metallic inclusions in formation of acicular ferrite in low alloy weld metals, Mater. Sci. Technol., v.12, n.3, p. 237-260, 1996.

[9] ZHANG, S. et al. Ferrite nucleation at ceramic/austenite interfaces, ISIJ Int., v. 36, n.10, p.1301-1309, 1996.

[10] JIN, H.H. et al. Formation of intragranular acicular ferrite grains in a Ti-containing low carbon steel, ISIJ Int., v.43, n.7, p.1111-1113, 2003.

[11] BROOKSBANK, D.; ANDREWS, K.W. Stress associated with inclusions in steel: a photoelastic analogue and the effects of inclusions in proximity, J. Iron Steel Inst., v.210, n. 10, p.765$776,1972$.

[12] BYUN, J.S. et al. Non-metallic inclusion and intragranular nucleation of ferrite in Ti-killed C-Mn, Acta Mater., v.51, n.3, p.1593-1606, 2003.

[13] LIU, Z. et al. Nucleation of acicular ferrite on sulfide inclusion during rapid solidification of low carbon steel, ISIJ Int., v.47, n.12, 1781-1788, 2007.

[14] GARLAND, J.G. Weld pool solidification control, Metal Construction and the British Welding Journal, ISIJ Int., v.20, p.121-127, 1974.
[15] DAVIES, G.J.; GARLAND, J.G. Solidification structures and properties of fusion welds, International Metals Review, $\mathrm{n}$. 20, p.83-106, 1975.

[16] WILlingHAM, D.C.; BAILEY, N. Chemical grain refinement in submerged arc welds, Welding Research International v.7, n.1, p.28-45, 1977.

[17] HEINTZE, G.N.; MC PHERSON, R. Solidification control of submerged arc welds in steels by inoculation with Ti, Welding Journal, v.65, n.3, p.71s-82s, 1986.

[18] PARANHOS, R. P. R., PAYÃO, J.; ORTEGA, L. C. Efeito da adição de $\mathrm{B}$ e Ti na microestrutura e tenacidade do metal de solda obtido por arco submerso em juntas de dois passes. In: XXV Encontro Nacional de Tecnologia da Soldagem, 1999, Belo Horizonte.

[19] LINNERT, G.E. Welding Metallurgy: Carbon and Alloy Steels, Miami, USA, Ed. AWS, v. I, 4ª ed, 940 p., 1994.

[20] BABU, S.S.; David, S.A., Inclusion formation and microstructure evolution in low alloy steel welds, ISIJ Int., v.42, n.12, p.1344-1353, 2002.

[21] YU, D. et al. Austenite grain coarsening and formation of intragranular ferrite in HSLA steels deoxidized with Ti and Al, Materials Transactions, JIM, v.37, n.10, p.1554-1560, 1996.

[22] ARAUJO, R., V., A. Caracterização microestrutural do metal de solda depositado por arco submerso em chapas de aço-carbono estrutural. Dissertação (Mestrado em Engenharia Mecânica) - Universidade Estadual Paulista, Ilha Solteira, p. $118,2006$. 